\title{
Leitura em aulas de História: práticas e possibilidades de ensino-aprendizagem
} Reading in History classes: teaching-learning practices and possibilities

Lectura en clases de Historia: prácticas y posibilidades de enseñanza-aprendizaje

\author{
LiSIANE SIAS MANKE $\odot$
}

Universidade Federal de Pelotas, Pelotas, RS, Brasil.

\begin{abstract}
$\diamond$
\section{RESUMO}

O artigo objetiva discutir as práticas de leitura realizadas em aulas de História, indicando para o predomínio de um suporte de leitura em especial: o livro didático. O texto analisa ainda, possibilidades de ensino-aprendizagem que contribuam para promover a competência leitora dos estudantes. Para dar conta de tal proposta, consideramos os dados empíricos coletados a partir de observações de cunho etnográfico em duas turmas de $9^{\circ}$ ano, à luz dos estudos que se ocupam em compreender a leitura enquanto prática cultural, que resulta da experiência social de leitores ativos. As aulas observadas possibilitam entender e problematizar a forma como a escola promove (ou não) meios para desenvolver a competência leitora.
\end{abstract}

Palavras-chave: Práticas de leitura. Aulas de História. Formação leitora.

\begin{abstract}
The purpose of this text is to analyze reading practices carried out in History classes, indicating, in particular, the predominance of reading support: the textbook. Finally, the text discusses teaching-learning possibilities that promote students' reading competence. To account for such a proposal, we analyzed the empirical data, collected from ethnographic observations in two 9th grade classes, in the light of studies that focus on reading comprehension as a cultural practice, resulting from active readers' social experience. The observed classes make it possible to understand and problematize the way a school promotes (or not) means to develop students' reading competence.
\end{abstract}

Keywords: Reading practices. History class. Reading formation.

\section{RESUMEN}

El artículo objetiva discutir las prácticas de lectura realizadas en clases de Historia, indicando para el predomínio de uno soporte de lectura en especial: el libro didáctico; aún, el texto analiza posibilidades de enseñanza-aprendizaje que contribuyan para promover la cualificación lectora de los estudiantes. Para dar cuenta de tal propuesta, consideramos los datos empíricos, recolectados a partir de observaciones de cunho etnográfico en dos turmas de $9^{\circ}$ año, a la luz de los estudios que se ocupan en comprender la lectura mientras práctica cultural, que resulta de la experiencia social de lectores activos. Las clases observadas posibilitan entender y problematizar la forma como la escuela promueve medios (o no) para desarrollar la cualificación lectora.

Palabras clave: Prácticas de lectura. Clases de Historia. Formación lectora. 


\section{INTRODUÇÃo}

Diante de indicativos que apontam resultados negativos em relação ao domínio da leitura e da escrita por indivíduos escolarizados ${ }^{1}$, implicando no fenômeno do analfabetismo funcional ${ }^{2}$, compreender o uso que se faz da leitura e da escrita em práticas escolares e meios para o desenvolvimento eficaz dessas práticas é premente. Solé (1998), direcionando o olhar para a instituição escolar, nos convida a ultrapassar o debate sobre os métodos mais adequados para o processo de ensino-aprendizagem da leitura, e centrar a discussão na conceitualização do que é leitura, ou seja, pensar e problematizar a forma como a escola promove elementos para produzir as competências necessárias para a execução da capacidade leitora. A partir dessa perspectiva, neste texto temos como propósito direcionar a análise para as práticas de leitura desenvolvidas por alunos e professores nas aulas de História; disciplina escolar que se utiliza na maioria das vezes, de textos escritos para desenvolver os conteúdos históricos. As experiências individuais e coletivas que envolvem esse saber são alimentadas, notadamente, por práticas provenientes dos espaços escolares, assim como, pelo uso de livros didáticos que veiculam esse conhecimento. De modo mais específico, o artigo objetiva discutir as práticas de leitura realizadas durante as aulas de História, indicando para o predomínio de um suporte de leitura em especial: o livro didático; por fim, o texto ocupa-se em analisar possibilidades de ensino-aprendizagem para a competência leitora. Para dar conta de tal proposta, consideramos os dados empíricos coletados em duas escolas públicas, à luz dos estudos que se ocupam em compreender a leitura enquanto prática cultural, que resulta da experiência social e da competência de leitores ativos (LAHIRE, 2002, 2004; SOLÉ, 1998).

A questão principal do estudo surgiu de discussões realizadas com alunos estagiários do curso de licenciatura em História, que ao realizarem o estágio de observação em turmas de educação básica problematizavam dois aspectos em especial: a forma como os livros didáticos eram utilizados nas aulas de História e as dificuldades de leitura e produção de sentidos dos estudantes. Tais questões colocavam em debate a compreensão (ou não) do conhecimento histórico por esses alunos. Com o intuito de desenvolver tais problematizações, alguns

\footnotetext{
1 A pesquisa "Retratos da Leitura no Brasil", de 2015, indica que apesar de ter aumentado o percentual da população alfabetizada entre 2001 e 2011, apenas 1 em cada 4 brasileiros domina plenamente as habilidades de leitura, escrita e matemática (FAILLA, 2016, p. 231).

2 Os resultados do Indicador de Alfabetismo Funcional (INAF), de 2015, apontam que entre os indivíduos que ingressaram ou concluíram os anos finais do ensino fundamental, um terço (34\%) ainda podem ser classificadas na condição de analfabetismo funcional (INAF, 2016, p. 8).
}

estudos pontuais foram realizados nas escolas em que os licenciandos realizaram seus estágios, consistindo basicamente na aplicação de questionários objetivos, que contribuíram para um diagnóstico inicial e para definir abordagens posteriores. Em um segundo momento, a pesquisa teve continuidade com observações de cunho etnográfico ${ }^{3}$ em duas salas de aula, com turmas de $9^{\circ}$ ano do Ensino Fundamental, de escolas distintas ${ }^{4}$ localizadas na periferia do município de Pelotas $/ \mathrm{RS}^{5}$. As observações ocorreram em um período de quatro meses, resultando em 38 aulas observadas, cada aula com duração de 45 minutos; 16 aulas na escola A e 22 aulas na escola $\mathrm{B}^{6}$. As notas de campo realizadas durante as observações in loco foram ampliadas após cada aula observada, com descrições minuciosas das atividades desenvolvidas por professores e alunos. Também foram coletados dados socioculturais dos alunos, por meio da aplicação de questionário, e dados sobre a formação e tempo de atuação dos professores de História das turmas observadas.

Conhecer a sala de aula, os embates, os sobressaltos, e as vivências que decorrem unicamente dessas relações, requer inicialmente um exercício de estranhamento a um espaço que parece familiar ao pesquisador. Conforme Pfaff (2013, p. 266), as pesquisas etnográficas desenvolvidas em espaços escolares estão voltadas, especialmente, para a análise de aspectos culturais e sociais que envolvem os grupos escolares e as questões relacionadas à organização escolar, mas ainda são pouco utilizadas para compreender as práticas de ensino e aprendizagem. A escola é lugar de socializações, de descobertas, de cerceamento, de enquadramento às lógicas sociais; ela é também um lugar de ensino e aprendizagem, um lugar de sujeitos ativos, que fazem a estrutura intocável dessa instituição ser diferente a cada dia. Neste estudo exercitamos o olhar de estranhamento em relação às práticas escolares, mantendo o foco nos alunos, sem desconsiderar as relações sociais por eles estabelecidas com os demais agentes do cotidiano escolar, em especial, os professores.

Entre as diversas práticas experienciadas no espaço escolar, nos ocuparemos das práticas de leitura, enquanto

\footnotetext{
${ }^{3}$ Conforme Pfaff (2013) a etnografia se compreende como uma abordagem metodológica, que inclui diferentes formas de coleta de dados, sendo uma prática social na qual o pesquisador toma parte da realidade social investigada.

${ }^{4}$ Nesta fase da investigação contamos com uma bolsista de iniciação a pesquisa do PIBIC CNPq.

5 A seleção dessas duas turmas ocorreu devido à disponibilidade dos professores para a realização das observações durante suas aulas, mediante autorização da Secretária Municipal de Educação e Desporto. Outro aspecto considerado, foi a indicação de que esses professores trabalhavam basicamente com o livro didático em suas aulas, sendo inicialmente, os usos do livro didático de História um dos aspectos perseguidos pela investigação.

${ }^{6}$ Foram observadas sequencialmente todas as aulas que ocorreram entre abril e julho, não sendo considerados os períodos em que estávamos na escola para realizar a observação e, por motivos diversos, não houve aula de História.
} 
prática cultural modelada a partir da relação estabelecida entre o leitor e o texto. Consideramos o que indica Lahire (2002), ao afirmar que os indivíduos são sensíveis às experiências sociais vivenciadas, que produzem modos múltiplos de ser e sentir, de forma que, a constituição do leitor está associada aos esquemas de sua experiência. O gosto por determinadas obras, os modos de ler, a interpretação e a modelagem do sentido do texto, são resultado de um processo individual que transparece a identidade do leitor, contribuindo para a produção de sentidos coletivos no contexto da sala de aula.

Desenvolver estratégias para a compreensão leitora ${ }^{7}$ no espaço escolar, em práticas coletivas de leitura, é parte indispensável para o processo de construção de significados do texto e para a atuação ativa do aluno leitor. Por "leitor ativo" entendemos o indivíduo capaz de processar e atribuir sentido ao código escrito. Para tanto, "é imprescindível o leitor encontrar sentido no fato de efetuar o esforço cognitivo que pressupõe a leitura, e para isso tem de conhecer o que vai ler e para que fará isso" (SOLÉ, 1998, p. 44). Assim, a interpretação leitora decorre da expectativa (objetivo da leitura), da motivação e do conhecimento prévio de cada leitor em relação ao tema do texto que irá ler; o que pode resultar em diferentes interpretações sobre o mesmo conteúdo, "pois a compreensão que cada um realiza depende do texto que tem à sua frente, mas também depende muito de outras questões, próprias do leitor" (SOLÉ, 1998, p. 40).

De modo semelhante, o sociólogo Bernard Lahire (2002), ao referir-se à apropriação da leitura, apresenta tal concepção como sendo a experiência que os leitores vivem com os livros. Para o autor, a leitura enquanto experiência social não pode ser comparada ao "consumo cultural", mas deve estar vinculada à "teoria da ação", pois "longe de ser uma atividade passiva e desconectada dos cursos da ação, a leitura tem posse da ação" (LAHIRE, 2002, p.98). As práticas de leitura, assim como os sentidos atribuídos ao texto, podem variar conforme o momento da trajetória social do leitor, de sua situação social (criança, adolescente, adulto, idoso, casado, divorciado...), ou diante das experiências sociais que o marcaram intensamente. Essa perspectiva contraria às abordagens que consideram o ato de ler como uma relação transparente entre o leitor e o texto, reduzindo este ao seu conteúdo semântico, sem relação com o suporte que o apresenta e com os modos e meios de ler ${ }^{8}$. De igual modo, Chartier (1994), ao discutir o conceito de apropriação, considera

\footnotetext{
7 Entendemos por compreensão leitora "o processo por meio do qual são postas em funcionamento as estratégias cognitivas e habilidades necessárias para compreender, que permitem que o leitor extraia e construa significados do texto, simultaneamente, para fazer sentido da língua escrita" (KLEIMAN, 2014, p. 61).

${ }^{8}$ Sobre práticas de leitura e sua apropriação por leitores ativos baseamonos em Certeau (1994) e Chartier (1994).
}

as práticas de leitura enquanto processos de interpretações socialmente constituídas, resultado da ação e interação entre o leitor (e seu conhecimento experiencial), o texto (e seu conteúdo semântico) e as obras (compostas por dispositivos discursivos e tipográficos). De forma que, a leitura permite elaborar, vivenciar ou constituir através dos sentidos atribuídos, os esquemas de experiências interiorizados e as identidades individuais.

O leitor com competência leitora é capaz de produzir sentidos sobre o que lê, e assim, privilegia certos temas em detrimento de outros, conhece outros lugares a partir de leituras relacionadas ao que lhe é conhecido, recria, interpreta, vive o momento diante das possibilidades que o "mundo da leitura" oferece. Para Goulemot (2001), são essas atitudes do leitor, nas quais estão relacionadas também as maneiras de ler, que possibilitam a produção de sentidos ao texto lido. Assim, o autor define de tal forma $o$ ato de ler:

Ler é dar um sentido de conjunto, uma globalização e uma articulação aos sentidos produzidos pelas sequências. Não é encontrar o sentido desejado pelo autor, o que implicaria que o prazer do texto se originaria na coincidência entre o sentido desejado e o sentido percebido, em um tipo de acordo cultural, como algumas vezes se pretendeu, em uma ótica na qual o positivismo e o elitismo não escaparão a ninguém. Ler é, portanto, constituir e não reconstituir um sentido (GOULEMOT, 2001 , p. 108).

Para o autor, a leitura resulta na revelação de sentido diante da polissemia que compreende o texto. Essa relação entre o leitor e a leitura é denominada por Goulemot (2001, p. 110) como "fora-do-texto", resultado de uma história coletiva e pessoal.

Em convergência com essa abordagem, partilhamos da ideia de que a aprendizagem da leitura, que se desenvolve ao longo de toda a escolaridade, está condicionada tanto à capacidade do aluno de processar o texto, em seus diferentes elementos (textuais e tipográficos), quanto às estratégias de leitura que contribuam para a produção de sentidos. Como bem expressa Solé (1998, p.24): "para ler é necessário dominar as habilidades de decodificação e aprender as distintas estratégias que levam à compreensão". Para a autora ensinar estratégias de leitura consiste em pensar sobre o ato de ler e planejálo; a partir de procedimentos que antecedem a leitura, como, objetivos a serem realizados, atualização de conhecimentos prévios, previsões sobre o texto; assim como atividade realizadas durante a leitura, como fazer perguntas, expor sucintamente o que foi lido, verificar dúvidas e, por fim, após a leitura, ensinar a construir a ideia principal do texto em função dos objetivos de leitura perseguidos inicialmente. Ainda, segundo a autora: 
Quando um professor pede aos seus alunos que digam "o mais importante deste capítulo", "o que o autor quis transmitir", ou quando esta recomendação aparece nos guias didáticos, é fundamental entender que não estamos ensinando a encontrar a ideia principal. Nestes casos estamos verificando se o aluno pôde ou não encontrá-la, em um ato que substitui o ensino pela avaliação, o que é bastante frequente na instrução da leitura (SOLÉ, 1998, p. 138).

A partir do que foi exposto, algumas questões nos mobilizam: Como se lê nas aulas de História das turmas observadas? O que é lido durante estas aulas? Como se produz conhecimento histórico no contexto escolar em evidência? Questionamentos que iremos perseguir a partir da análise dos dados empíricos.

\section{O LIVRO DIDÁtico E A LEITURA NAS AULAS DE História}

A coleta de dados foi realizada, como já referido, a partir de observações de cunho etnográfico realizadas em duas turmas de $9^{\circ}$ ano, durantes as aulas de História, resultando em 16 aulas observadas na escola A e 22 aulas na escola B. As turmas serão caracterizadas em termos socioeconômicos, tendo por base o nível de formação e a profissão das famílias, indicados no questionário respondido pelos alunos. Na classe da escola $\mathbf{A}$, composta por 14 alunos (13 meninas e um menino), com idades entre 13 e 16 anos, mais da metade dos pais e das mães possui apenas o Ensino Fundamental; dentre as profissões desempenhadas pelos homens, consta: marceneiro, borracheiro, caminhoneiro, vigilantes, entre outras profissões do setor de serviços. No caso das mulheres, a principal ocupação é ser dona de casa, ou ainda, faxineira, balconista e cabelereira, para dar alguns exemplos. Na turma da escola $\mathbf{B}$, a situação socioeconômica dos alunos é semelhante. Entre os 26 alunos (10 meninas e 16 meninos), com idades entre 13 e 16 anos, a formação dos pais restringe-se ao Ensino Fundamental, enquanto a maioria das mães possui Ensino Médio. A quase totalidade dos pais atua nas seguintes profissões: caminhoneiro, padeiro, pedreiro, vendedor e mecânico; enquanto boa parte das mães são donas de casa ou prestam serviços não especializados, com exceção de uma que é professora. Trata-se, portanto, de famílias que, possivelmente, possuem pouco acesso a bens socioculturais, sendo a escola uma importante instância de socialização para os filhos ${ }^{9}$.

\footnotetext{
9 Frisamos, contudo, que a origem socioeconômica dos alunos não é determinante para o desempenho escolar. Sobre a crítica ao funcionamento das lógicas sociais a partir de dados estatísticos, que classificam de forma grosseira as condições econômicas e culturais a partir da profissão do chefe de família, ver Lahire (1997).
}

Ambos os professores possuem licenciatura em História e são docentes efetivos da rede municipal de educação, com regência de turma apenas na disciplina de História. O professor da escola A possui experiência de mais de 20 anos na educação básica, enquanto o professor da escola $\mathbf{B}$ tem aproximadamente 15 anos de atuação em séries finais do Ensino Fundamental. De modo geral, os professores demonstram significativa motivação para o desempenho da docência, e estabelecem boa relação com os alunos. Mas que papeis desempenham esses professores e esses alunos durante as aulas de História?

A primeira constatação em relação ao circuito didático, discutido por Rocha $(2009,2006)$, como sendo a trama de ações rotineiras que se desenvolve entre professores, alunos e conhecimento histórico escolar, em uma sequência de início, meio e fim, durante o horário escolar, foi no sentido de que o livro didático é lido em praticamente todas as aulas. A centralidade do livro e o predomínio de práticas de leitura constituem, essencialmente, o conteúdo das atividades realizadas durante as 38 aulas observadas. O Quadro 1, adiante, sistematiza esses dados.

Das 16 aulas ministradas de abril a julho na escola A, o professor utilizou o livro didático em 14 aulas; em 11 dessas aulas o livro foi tomado como suporte de leitura, em práticas diversas: leitura oral de fragmentos do texto, seguida de comentários do professor; leitura oral compartilhada entre alunos e professor, leitura silenciosa para feitura de exercícios. Em duas das demais três aulas, os alunos utilizaram o livro para copiar textos para o caderno, e em uma aula o professor tomou como base um texto do livro para fazer a exposição oral do conteúdo.

$\mathrm{Na}$ escola B, foram observadas 22 aulas ministradas no mesmo período. Em 17 aulas o professor usou o livro didático, e em grande parte das aulas em que o livro foi utilizado, a didática empregada esteve relacionada à prática de leitura oral. Embora tenha havido diferentes modos de ler - leitura compartilhada, leitura seguida de comentários, leitura individual, leitura para realização de exercício -, a leitura oral foi a prática predominante. Em seis aulas, o professor leu e comentou o conteúdo para os alunos, sem contribuição ou participação deles. Em uma dessas aulas o professor não comentou o conteúdo, apenas leu o livro para os alunos durante toda a aula.

Os dados organizados desse modo nos possibilitam visualizar a recorrência e predomínio do livro como recurso didático, e o uso dessa ferramenta em atividades envolvendo a prática de leitura oral durante as aulas. Devemos considerar, portanto, a centralidade da figura do professor durante as aulas observadas; é ele que indica o que deve ser lido, por quem deve ser lido, o modo como deve ser lido, e por vezes, é somente ele quem lê. Contudo, é necessário ter em vista que embora o livro didático 
Quadro 1 - Classificação das atividades realizadas nas aulas de História*

\begin{tabular}{|c|c|c|}
\hline $\begin{array}{l}\text { Atividades que predominaram nas } \\
\text { aulas observadas }\end{array}$ & $\begin{array}{c}\text { ESCOLA A - } 16 \text { aulas } \\
\text { № de aulas c/ atividade citada }\end{array}$ & $\begin{array}{c}\text { ESCOLA B - } 22 \text { aulas } \\
\text { № de aulas c/ atividade citada }\end{array}$ \\
\hline $\begin{array}{l}\text { Aulas que tiveram por base o livro didático } \\
\text { (para leitura, realização de atividades ou cópia). }\end{array}$ & 14 aulas & 17 aulas \\
\hline $\begin{array}{l}\text { Aula com exibição de filmes, curtas ou } \\
\text { documentários. }\end{array}$ & Nenhuma & $\begin{array}{c}5 \text { aulas. } \\
\text { Em duas dessas aulas o livro } \\
\text { foi utilizado paralelamente ao } \\
\text { documentário. }\end{array}$ \\
\hline Aulas com avaliação ou para fechamento de notas. & 2 aulas & 2 aulas. \\
\hline $\begin{array}{l}\text { Aula sem leitura, com exposição oral do professor a } \\
\text { partir do livro. }\end{array}$ & 1 aula & Nenhuma \\
\hline $\begin{array}{l}\text { Aulas em que somente o professor leu o livro didático } \\
\text { para os alunos, comentando o conteúdo. }\end{array}$ & 1 aula & $\begin{array}{c}6 \text { aulas } \\
\text { Em uma dessas aula não houve } \\
\text { comentários, somente a leitura oral } \\
\text { do professor. }\end{array}$ \\
\hline $\begin{array}{l}\text { Aulas em que o professor e os alunos partilharam } \\
\text { a leitura do livro didático, seguido por comentários } \\
\text { sobre o conteúdo. }\end{array}$ & 5 aulas & 3 aulas \\
\hline $\begin{array}{l}\text { Aulas em que os alunos realizaram a leitura do livro } \\
\text { para responderem questões. }\end{array}$ & 3 aulas & 3 aulas \\
\hline $\begin{array}{l}\text { Aulas em que os alunos copiaram do livro didático } \\
\text { para o caderno. }\end{array}$ & 2 aulas & Nenhuma \\
\hline
\end{tabular}

* Apresenta os dados coletados nas observações etnográficas, em relação as atividades desenvolvidas durante as aulas.

Fonte: Elaborado pela autora.

seja utilizado predominantemente com a mediação do professor, o mesmo é produzido e pensado para um determinado público: o alunado. Com bem expressa Batista (2000), "a destinação a esse leitor é evidente na organização e na linguagem dos textos e impressões e em sua utilização. O prefácio e a apresentação dos livros se dirigem ao aluno; nos exercícios e atividades, as instruções também [...]" (BATISTA, 2000, p. 551). Desse modo, entre o autor/editor e o leitor visado ${ }^{10}$ (o aluno) há que se considerar o significativo papel desempenhado pelo professor, que vai da escolha do livro que seus alunos irão utilizar à apropriação dos sentidos produzidos nas leituras realizadas neste suporte.

Para a análise das atividades envolvendo a leitura do livro didático optamos em descrever as ações ocorridas em algumas aulas, que representam as práticas mais recorrentes observadas. Para essa descrição utilizamos a concepção de circuito didático (ROCHA, 2006), para assim descrever o evento aula de História.

DesCrição 1: O professor da escola A começa a aula solicitando a entrega do trabalho da aula anterior, (no qual as alunas ${ }^{11}$ deveriam escolher entre Cangaço, Contestado

\footnotetext{
${ }^{10}$ Utilizamos aqui a abordagem discutida por Umberto Eco (2004), a partir da concepção de leitor modelo.

${ }^{11}$ Marcamos o gênero feminino ao nos referirmos a esta turma, por ser majoritariamente feminina.
}

e Canudos para realizar uma pesquisa). Posteriormente, distribui os livros didáticos e pede que abram na página 62, faz uma exposição oral sobre direitos trabalhistas e lutas operárias, depois começa a ler o tópico "As primeiras lutas e conquistas operárias". Sem comentar o que havia lido, o professor pergunta se alguém quer continuar lendo. Uma aluna se manifesta e tem permissão para ler, ela troca algumas palavras, mas o professor não a corrige. Ao concluir o tópico o professor não questiona se entenderam o que foi lido, e segue explicando sobre as caixas de aposentadorias. Ao final desta explicação, questiona: "- Alguma pergunta?". As alunas respondem que "não". Em seguida, pede que abram o livro nas páginas 68 e 69, e solicita que outra aluna leia. A aluna lê com dificuldade algumas palavras, que são corrigidas por uma colega. Por exemplo, lê "dissolução", a colega a interrompe dizendo: "é resolução". Ainda lê "século xis i xis e xis xis", demonstrando dificuldade na leitura de séculos, e é corrigida novamente pela mesma colega. Por fim, se inicia uma conversa na turma sobre a cidade do Rio de Janeiro (tema do texto da página 68), que perdura até o final da aula.

DESCRIÇÃO 2: O professor começa a aula falando sobre a data de 22 de abril, problematiza a questão dizendo que os portugueses não teriam descoberto, mas sim invadido o Brasil. Também dá algumas explicações sobre a data 
do dia anterior, 21 de abril, questionando as alunas se sabem quem teria sido Tiradentes. A discussão passa a ser pena de morte, a partir do assunto "morte do Tiradentes", e continua com a temática "drogas"; as alunas riem e gritam de forma eufórica sobre exemplos vivenciados no dia a dia. Quando faltam apenas 15 minutos para acabar a aula, o professor pede que duas alunas busquem os exemplares do livro didático na biblioteca. Quando as estudantes recebem o livro, o professor abre o seu exemplar na página 64 , sem indicar a página que seria lida; lê três tópicos, sem interrupção, sobre a Semana da Arte Moderna, sem estabelecer conexão com o que estava sendo discutido. Posteriormente, passa para a página 65 , onde lê mais dois tópicos; ao concluir não pergunta se há dúvidas. Durante a leitura, é possível perceber que a maioria das alunas não acompanha a leitura do livro didático, embora o livro esteja aberto. No fim da aula, o professor solicita que as alunas escutem músicas do compositor Heitor Villa Lobos, citado na leitura da página 65, e tragam em um pen drive para o dia da exposição das telas que serão produzidas sobre a Semana de Arte Moderna. Neste momento soa o sinal avisando do término do período.

A descrição dessas aulas, que representam com pouca variação as atividades desenvolvidas nas demais, possibilita perceber que o livro didático é o principal recurso didático, exercendo função referencial. A metodologia de uso fica restrita basicamente a leitura, realizada normalmente de forma oral. Algumas estudantes costumam solicitar a vez para ler o livro, recorrentemente as mesmas, o que é permitido, de modo geral, pelo professor, enquanto as demais apenas acompanham. Outras ainda, distraem-se enquanto as colegas leem. Contudo, há também uma aluna que normalmente é escolhida pelo professor para ler, provavelmente por ter uma leitura tranquila e pausada. Uma outra, que lê muito rápido, e outra, que lê separando as sílabas, apesar de não serem solicitadas, pedem a permissão para ler, enquanto as demais não manifestam a vontade de ler, e também não são demandadas a fazerem.

O circuito didático desenvolvido pelo outro professor da escola B, será analisado em três aulas sequenciais, selecionadas por apresentarem certo encadeamento entre as aulas (ou não), e também, por serem atividades mais recorrentes nas demais aulas.

DESCRIÇÃo 1: O professor começa avisando que não vai entregar os livros didáticos, pois terão apenas um período de aula (os livros ficam na biblioteca). Mas abre o seu próprio exemplar e lê o texto sobre o qual os alunos responderam duas questões na aula anterior. Durante a leitura, alguns alunos observam o professor, enquanto outros, parecem distraídos. Ao concluir a leitura, chama atenção para uma charge presente no livro; os alunos, mesmo sem o livro didático, são estimulados a recordarem-se da charge e assim respondem às perguntas do professor. Posteriormente, inicia a correção das questões realizadas na aula anterior, solicitando que alguns alunos leiam a resposta, que é comentada por ele. Nos últimos 10 minutos da aula, o professor ocupa-se em organizar o mapa de sala, fixando os locais em que cada aluno deverá assentar-se.

DESCRIÇÃo 2: O professor inicia a aula perguntando se os estudantes estão seguindo o mapa de sala com os demais professores, diz que é para o bem deles e rendimento das atividades. Em seguida, convida dois alunos a irem com ele buscar os livros didáticos $\mathrm{e}$ orienta os demais a formarem duplas para realizarem um trabalho. Ao retornar, começa a explicar o conteúdo das páginas 150 e 151 do livro didático, para depois explicar o trabalho que seria feito a partir dos exercícios da página 152. O professor faz uma breve explanação do conteúdo, depois passa a ler e comentar um quadro sobre os direitos trabalhistas criados no governo Vargas. Em seguida, passa a ler o tópico "O Brasil na Segunda Guerra Mundial” da mesma página. A maioria dos alunos olha para o livro didático acompanhando a leitura. Duas meninas, sentadas na frente, começam a conversar, o professor faz uma pausa para chamar atenção delas. Após, o professor lê mais três tópicos de forma ininterrupta. Durante essa leitura, apenas faz uma pausa para reclamar da conversa das mesmas meninas. Neste momento, um aluno faz um comentário, dizendo: "Mas Hitler queria dominar o mundo, o Getúlio não". O professor responde que a aproximação entre a Alemanha nazista e o Brasil de Vargas está na repressão àqueles que discordam do governo e não na existência das eleições. O professor dá continuidade e finaliza a leitura, sem questionar os estudantes se entenderam o conteúdo, ou mesmo o vocabulário do texto. Em seguida, solicita que façam duas questões da página 152. Então, sai da sala por um momento. As duplas já organizadas começam a trabalhar, com exceção de algumas duplas que conversam baixo sobre outros assuntos. No momento em que terminam a atividade, entregam para o professor o livro didático, e são liberados.

DesCRIÇÃo 3: O professor começa a aula lembrando aos alunos que devem trazer a maquete de Brasília, ou de um prédio, para a próxima aula, os alunos reclamam do trabalho, e mostram-se desmotivados (essa atividade que foi solicitada antes de iniciarmos as observações). O professor sai para buscar os livros, ao retornar diz: "Tá aqui os livros, se faltar para alguém sentem-se em dupla, página 206", (o professor altera a sequência de conteúdos apresentada no livro, desenvolvendo em suas aulas apenas questões ligadas à História do Brasil.) Após comentar sobre a prova que será aplicada na aula seguinte, começa a ler o texto com o título "Os anos dourados do Brasil". 
Ao concluir, pergunta: "O que vocês pensam sobre isso?" Um aluno afirma: "Os anos de ouro". O professor confirma que significa que foram bons anos para o país, e continua a ler. Ele interrompe a leitura algumas vezes para chamar a atenção dos alunos que conversam, enquanto outros acompanham a leitura. O professor lê o tópico de maneira completa e faz algumas explicações sobre a construção de Brasília. Parte da turma fica bastante distraída durante a leitura. O professor continua lendo o tópico "O crescimento econômico", pausando várias vezes para explicações, chamando atenção para questões atuais, como a importância do $\mathrm{ABC}$ paulista hoje. E posteriormente, lê o tópico "Brasília, o sonho realizado de JK". Ao concluir a leitura na íntegra desse tópico, questiona os alunos sobre o que significa "concentração de renda"; alguns alunos ensaiam uma resposta, e o professor passa a explicar a questão. Então, o sinal soa indicando o final da aula.

De forma similar ao circuito didático organizado na escola A, o professor da escola B também utiliza somente o livro como recurso didático, e a metodologia empregada é a leitura oral dos textos, realizada unicamente por ele, seguida de exposições orais. Em outras aulas, de forma esporádica, o professor solicita que alguns outros alunos leiam, mas grande parte da turma nunca lê. De modo geral, a participação dos alunos é bastante restrita, o professor questiona se há dúvidas, mas pouco dialoga com os alunos sobre a leitura que realizaram. Ainda, observamos que a maioria das questões que faz à turma após a leitura, dizem respeito ao significado de termos e expressões que aparecem no livro didático, poucas perguntas refere-se ao entendimento do texto lido.

Contudo, devemos considerar o empenho dos professores para que o conteúdo seja exposto durante as aulas, e para que os alunos assimilem os acontecimentos históricos que estão sendo transmitidos a partir da leitura do livro. No entanto, produzir sentidos coletivos a partir das percepções individuais, requer a definição de objetivos, previsão, inferência, observação dos dispositivos textuais, estabelecimento de pontes conceituais entre o conhecimento prévio do leitor e o conteúdo do texto lido. Como bem indica Solé (1998), para o desempenho da compreensão leitora é importante a construção de sínteses sobre o texto, de forma oral ou por escrito, ainda durante a leitura. Para que, após a leitura, seja possível construir resumos que contemplem a ideia principal do texto e das relações que o leitor estabelece com ele, a partir dos objetivos de leitura e dos conhecimentos prévios do leitor.

Outro aspecto a ressaltar diz respeito ao livro didático, ambos os professores utilizam em suas aulas o livro Projeto Araribá: História, do 9으 ano, obra coletiva editada pela Editora Moderna. Trata-se de uma obra de grande aceitação na rede pública de ensino, sendo um dos livros mais adquiridos nas últimas edições do PNLD História. Entre os propósitos da coleção, que possui livros para diferentes disciplinas, está a concepção de ensino da leitura como compromisso de todas as áreas do Ensino Fundamental, inclusive da disciplina de História. Contudo, para Silva (2009), que analisa as concepções de ensino dessa obra, há ausência de fundamentação teórica no campo da leitura, pois os autores não apresentam um conceito específico de leitura em História, "neste caso, a chamada competência leitora (termo adotado pelo material) seria uma competência geral, sem especificidades por área de conhecimento, para a qual todas as disciplinas deveriam trabalhar" (SILVA, 2009, p. 162). Outro pesquisador que se ocupou em problematizar o uso do livro Projeto Araribá, Silva (2012), considera que o conceito de competência leitora presente na obra é tomado como postulado totalizante na constituição da obra, sendo motivado explicitamente pelos resultados do PISA 2000, que indica os baixos níveis de leitura e letramento da população brasileira. Neste sentido, apesar de ser um propósito da coleção desenvolver a competência leitora dos alunos, não há encaminhamentos específicos em termos didático-pedagógicos que auxiliem o professor a desenvolver essa competência.

Portanto, se esses autores apontam que há contradições entre a proposta pedagógica da coleção Projeto Araribá e a forma como os conteúdos são desenvolvidos no livro, distanciamentos também podem ser observados entre a proposta da obra e a prática pedagógica observada nas duas turmas de $9^{\circ}$ ano. Como bem considera Bittencourt (2013. p. 73), para entender o papel que o livro didático estabelece na vida escolar não basta analisar a ideologia, a defasagem ou a fidelidade do material em relação às propostas curriculares. Para a autora, os livros didáticos são portadores de textos que podem auxiliar o domínio da leitura e da escrita em todos os níveis de escolarização, entre outros tantos aspectos. Contudo, é necessário considerar que o livro passa pela intervenção de professores e alunos que fazem diferentes usos desse material, por vezes, potencializando seus conteúdos; outras vezes, negligenciando textos e propostas pedagógicas (BITTENCOURT, 2013, p. 74).

A análise do circuito didático das aulas observadas não pretende avaliar a prática pedagógica dos professores e a eficácia dos procedimentos metodológicos adotados. As atividades desenvolvidas nas duas turmas tiveram como propósito promover o conhecimento histórico dos alunos, para isso os professores realizaram a leitura oral do livro, explicaram o conteúdo, propuseram atividades, e aplicaram avaliações, assim, o evento aula de História foi efetivado em todos os seus aspectos, a partir da concepção de ensino-aprendizagem de cada professor. Contudo, as práticas observadas possibilitam compreender e 
problematizar a forma como a escola promove meios (ou não) para desenvolver as práticas de leitura de seus alunos, visando a promoção da competência leitora, e a autonomia dos alunos.

\section{ENSINAR A LER PARA PRODUÇÃo DE SENTIDOS}

A análise das aulas observadas permite considerar que ao ler para os alunos os professores ocupamse em desenvolver o conteúdo histórico, a leitura é uma forma de comunicar o currículo escolar a partir do livro didático. Em uma das aulas o professor da escola A, diante da dificuldade de uma das alunas em compreender o vocabulário do texto que lia, afirma ser essa deficiência uma decorrência da ausência do hábito de ler, evidenciando, de algum modo, que a prática realizada durante a aula de História não serve como exercício de leitura. Nesse sentido, ensinar a ler, interpretar, ampliar o vocabulário, produzir interpretações, sintetizar, parecem ser verbos que ainda estão restritos à disciplina de Língua Portuguesa. As leituras realizadas pelos alunos nas aulas de História, seja de forma oral ou enquanto leitores-ouvintes do livro didático, não carregam consigo o objetivo de produzir um sentido, a partir das percepções individuais. A interpretação sobre o conteúdo lido na sala de aula é realizada pelo professor, que produz comentários após a leitura, apontando os sentidos do texto lido, ou propondo atividades/questionários para que se chegue às ideias principais do texto, de forma fragmentada nesse caso. Desse modo, o que é central nas atividades realizadas é o comunicar do conteúdo de História, em detrimento de práticas que instrumentalizem o aluno a produzir individual ou coletivamente o conhecimento histórico.

De igual modo, os livros didáticos, por estarem vinculados às instâncias institucionais, refletem uma dada imagem das práticas da leitura. Ou seja, o livro didático encerra a intenção de controlar a recepção por parte do aluno leitor, que fica entre duas categorias contraditórias: de um lado, suas vivências e experiências anteriores que são trabalhadas no ato da leitura e, por outro, a necessidade de condicionar sua leitura a própria constituição do texto e seus dispositivos de leitura. Nesse sentido, o professor, como principal mediador, deve considerar que "a leitura do mundo que acompanha a leitura do livro didático será diferente para cada aluno leitor, terá características específicas, podendo mesmo tornar-se ininteligível ou despertar aversão por parte de alguns deles" (BARBOSA, 2009, p. 37). Assim, produzir sentidos a partir da leitura coletiva, requer cuidado, requer voltar ao texto, problematizar, contrapor ideias, partir do conhecimento experiencial de cada indivíduo, aparar arestas, e construir sentidos que verdadeiramente façam sentido para aquele coletivo, naquele determinado momento histórico. Demanda assim, estratégias de leitura que objetivam produzir leitores ativos, embora esse processo não seja simples em se tratando de uma coletividade, conforme observa Solé:

\begin{abstract}
Em uma classe, pode ser muito difícil contentar os interesses de todas as crianças com relação à leitura e fazê-lo coincidir com os do professor, que supostamente interpreta as prescrições das propostas curriculares. (...) Por outro lado, não devemos esquecer que o interesse também se cria, se suscita e se educa e que em diversas ocasiões ele depende do entusiasmo e da apresentação que o professor faz de uma determinada leitura e das possibilidades que seja capaz de explorar (SOLÉ, 1998, p. 43).
\end{abstract}

Em uma sequência de aulas rotineiras centrada na figura do professor, aspectos como motivação, estímulo à expressão de conhecimentos prévios, previsões sobre o texto, hipóteses a serem confirmadas com a leitura, não são percebidas como estratégias prévias à leitura, o que resulta em um processo automático de ler para adquirir um conhecimento "sem sentido", que terá como principal objetivo a aprovação na avaliação final da disciplina. A esse respeito exemplifica Lajolo (1996):

\begin{abstract}
É só a partir do conhecimento que já têm do mundo em que vivem, que os alunos poderão construir os conhecimentos nos quais livro didático e escola devem iniciá-los. Alunos, por exemplo, que acreditam que o leite azeda porque o saci cuspiu nele, dificilmente mudarão de opinião pela mera leitura de um texto que os informe sobre contaminação do leite como fruto da falta de higiene. No caso, é preciso partir do saci e chegar aos bacilos.... e essa passagem só o professor pode fazer, e é o que ele precisa fazer de mais importante (LAJOLO, 1996, p. 6).
\end{abstract}

Além da necessária relação com os conhecimentos prévios, a motivação para uma leitura que visa a produção de sentidos também está relacionada com a qualidade do suporte que é dado a ler; a materialidade e os dispositivos de leitura ${ }^{12}$ contribuem e interferem na apropriação que se faz do texto. A motivação para a leitura pode estar associada a um texto atraente em termos tipográficos, ou mesmo, que apresente uma linguagem adequada ao público a que se destina. Observar o livro ou o texto que será lido, estabelecer previsões sobre a leitura, levantar hipóteses sobre o tema a ser lido, são aspectos que fazem parte das estratégias de leitura que contribuem para desenvolver a competência leitora (SOLÉ, 1998). Para

\footnotetext{
${ }^{12} \mathrm{~A}$ respeito da relação entre materialidade dos suportes de leitura e apropriação do texto, consultar Chartier (2014) e Mckenzie (2005).
} 
tanto, lançar mão dos protocolos de leitura ${ }^{13}$ presentes nos textos é uma forma de familiarizar os estudantes com o que será lido e com as ideias principais que ele contém, ou seja, o professor ao explorar títulos, subtítulos, negritos, sumários, ilustrações, caixas de texto, e outros dispositivos presentes no livro/texto, contribui para que os alunos possam prever o assunto e o direcionamento que o autor $\mathrm{e}$ editor pretenderam dar para a leitura, preparando-se para o ato da leitura. Além disso, Solé (1998) considera que:

Todos esses indicadores também servem para ativar conhecimento prévio (antes da leitura) e serão úteis se depois tiver que extrair as ideias centrais do texto, elaborar um resumo ou fazer anotações sobre o que foi estudado (depois da leitura). (...) Estes organizadores (...) têm a função de estabelecer pontes conceituais entre o que o leitor já conhece e o que se deseja que aprenda e compreenda (SOLÉ, 1998, p.29).

Esses organizadores ou dispositivos raramente foram utilizados nas aulas observadas, considerando que os livros didáticos de História apresentam um significativo número de protocolos de leitura, ou seja, caixas de texto, ilustrações, subtítulos, conceitos históricos marcados em negrito, itálicos, entre outros. Observamos também, que os alunos não fazem uso do sumário dos livros, pois os professores costumam indicar a página, que é automaticamente localizada pelos estudantes. Assim, não há referência à unidade que está sendo trabalhada, nem conexão entre o que foi lido nas aulas anteriores e o que será desenvolvido na sequência. Notoriamente, os dispositivos de leitura são utilizados no momento em que os estudantes realizam as atividades, quando então recorrem a essas marcas para localizar a resposta das perguntas, para que não seja necessário ler ou reler o texto completo. Outro aspecto a ser considerado diz respeito ao que não é lido no livro didático, ou seja, dificilmente os boxes, quadros explicativos, imagens ou mapas são explorados durante a leitura oral, de modo a complementar e/ou ampliar o texto principal o livro didático.

Para Solé (1998), as práticas de leitura nas quais cada aluno lê um fragmento, enquanto os demais acompanham em seu próprio livro, e os erros são corrigidos pelos colegas ou professor, resultando na realização de perguntas e respostas sobre o texto lido, instala-se com bastante frequência na sala de aula, sendo atividade indicada em boa parte dos guias e livros didáticos, inclusive, independente do conteúdo curricular. Contudo, embora considerada como atividade de compreensão leitora, nessa "sequência

\footnotetext{
${ }^{13}$ Consideramos, aqui, protocolo de leitura uma espécie de acordo formal e explicitamente escrito (ou inscrito) que o autor de uma obra propõe a seu provável leitor, para norteá-lo, para estabelecer como deve conduzir a leitura do livro, sinalizando o tipo de leitura adequada (GALVÃO; BATISTA, 2009, p. 29).
}

há pouco espaço para as atividades destinadas a ensinar estratégias adequadas para a compreensão de textos", ou seja, no processo de ler e responder questões sobre o que foi lido, não se ensina a compreender, restringe-se à avaliação da compreensão leitora (SOLÉ, 1998, p.35). Para a autora, as estratégias de compreensão leitora não se localizam apenas no momento anterior à leitura, mas também no decorrer dessa e posterior a essa. A ideia principal, a síntese, se constrói durante a leitura, enquanto "produto da interação entre os propósitos que a causam, o conhecimento prévio do leitor e a informação aportada pelo texto" (SOLÉ, 1998, p. 31). É durante a leitura que os objetivos do ato de ler vão sendo contemplados, em um processo de ir e vir ao texto, sendo fundamental para o aluno leitor compreender o porquê de estar lendo.

Ainda, para Solé (1998), em se tratando de uma leitura compartilhada entre professor e alunos, após a leitura de um trecho, o professor pode solicitar a um aluno que faça uma recapitulação do que foi lido, assim, esclarece dúvidas, pergunta, prevê, e aumenta progressivamente o envolvimento dos participantes. Desse modo, uma atividade de leitura compartilhada deve priorizar a transferência da responsabilidade e do controle da tarefa de leitura das mãos do professor para a dos alunos. No processo defendido pela autora, a leitura compartilhada foge da sequência frequentemente realizada na escola, isto é, uma prática em que os alunos leem e respondem a perguntas, mas não as interiorizam, nem se responsabilizam pelo processo de aprendizagem (SOLÉ, 1998, p. 121). Um leitor ativo, pelo contrário, será responsável por produzir seus próprios sentidos sobre a leitura. Para tanto, precisa ser estimulado a comentar o que leu, provocado a compreender o que está nas entrelinhas do texto, instigado a dar sua opinião a partir do que leu e de seus conhecimentos prévios, possibilitando a produção de conhecimentos a partir de uma leitura competente.

\section{CONSIDERAÇÕES FINAIS}

A possibilidade de acompanhar o trabalho realizado nestas duas turmas nos permitiu algumas reflexões sobre o ensino de História e as práticas de leitura realizadas na escola. Presenciamos aulas que ocorreram efetivamente, que foram bem-sucedidas se considerarmos apenas o circuito didático, ou seja, o evento aula de História com início, meio e fim, no qual o conteúdo histórico foi desenvolvido a partir da leitura de textos didáticos compartilhados entre estudantes e professores. Contudo, as observações também permitem considerar que a apropriação do conhecimento histórico, enquanto conhecimento imbuído de sentido e significado, foi atingido de forma parcial. Questões diversas envolvendo 
o contexto escolar e as comunidades podem contribuir para este resultado, mas no que tange ao contexto da sala de aula e as atividades que nesse espaço se desenrolam, podemos considerar como aspecto significativo a ausência de estratégias de promoção da competência leitora, assim como da participação ativa dos alunos no processo de ensino-aprendizagem. Conforme o referencial teórico discutido, desenvolver estratégias de leitura, antes, durante e depois de ler, que levem em consideração o texto - em seus aspectos temáticos e semânticos -, o suporte de leitura - com dispositivos discursivos e tipográficos -, e os leitores - com suas competências e disposições sócio históricas (conhecimento experiencial) -, possibilita a formação do leitor com competência leitora.

Por fim, ao considerar que os textos didáticos lidos em sala de aula foram apresentados somente como condutores do conteúdo, percebemos que não houve a compreensão dos professores em relação a leitura como prática que possui posse de ação. Embora seja preciso ponderar que os cursos de formação docente pouco se ocupam em desenvolver aprendizagens sobre os processos de ensino e, mais especificamente, sobre a formação leitora no âmbito de todas as disciplinas escolares, alguns discursos não se sustentam mais; se os alunos não aprendem porque não sabem ler, o professor de História precisa assumir esse compromisso, ou seja, se leitores ativos são capazes de apropriarem-se de textos escritos para compreenderem os processos históricos vivenciados pela humanidade, será necessário lançar mão de estratégias de leitura, e ensinar a ler de forma competente. Um leitor ativo e autônomo será capaz não apenas de adquirir conhecimentos históricos, mas de dar significado para essa aprendizagem de acordo com a sua própria experiência histórica.

\section{REFERÊNCIAS}

BARBOSA, Raquel Lazzari Leite. Práticas de leitura e conceitos sócio-ambientais. São Paulo: Arte \& Ciências, 2009.

BATISTA, Antônio Augusto Gomes. Um objeto variável e instável: textos, impressos e livros didáticos. In: ABREU, Márcia (org.). Leitura, história e história da leitura. Campinas: Mercado de Letras/ALB/FAPESP, 2000. p. 529-575. https://doi.org/10.14393/che-v17n2-2018-19

BATISTA, Antônio Augusto Gomes. Livro didáticos entre textos e imagens. In: BITTENCOURT, Circe. O saber histórico na sala de aula. São Paulo: Contexto, 2013.

CERTEAU, Michel de. A invenção do cotidiano, artes de fazer. Petrópolis: Vozes, 1994.

CHARTIER, Roger. A ordem dos livros, leitores, autores e bibliotecas entre os séculos XIV e XVIII. Brasília: UnB, 1994.
CHARTIER, Roger. A mão do autor e a mente do editor. São Paulo: Editora Unesp, 2014.

ECO, Umberto. O leitor modelo. In: ECO, Umberto. Lector in Fábula. São Paulo: Perspectiva, 2004. p. 35-49.

FAILLA, Zoara (org.). Retratos da leitura no Brasil. Rio de Janeiro: Sextante, 2016. Disponível em: http:// prolivro.org.br/home/images/2016/RetratosDaLeitura2016 LIVRO_EM_PDF_FINAL_COM_CAPA.pdf. Acesso em: 17 fev. 2017.

GALVÃO, Ana Maria de; BATISTA, Antônio Augusto Gomes. O estudo dos manuais escolares e a pesquisa em história. In: BATISTA, Antonio Augusto G.; GALVÃO, Ana Maria de O. Livros Escolares de Leitura no Brasil: elementos para uma história. Campinas/SP: Mercado das Letras, 2009. https://doi.org/10.1590/s141324782002000200003

GOULEMOT, Jean Marie. Da leitura como produção de sentidos. In: CHARTIER, Roger (org.). Práticas de leitura. São Paulo: Estação Liberdade, 2001. p. 107-116.

INAF. Indicador de Alfabetismo Funcional: estudo especial sobre alfabetismo e mundo do trabalho do Instituto Paulo Montenegro. 2016. Disponível em: file://C:/Users/Lisiane/ Downloads/INAFEstudosEspeciais_2016_Letramento_e_ Mundo_do_Trabalho.pdf. Acesso e⿳亠丷厂 : $10 \overline{\mathrm{dez}} .2016 . \mathrm{https}: / /$ doi.org/10.11606/d.27.2011.tde-10062013-114554

KLEIMAN, Â. B. Compreensão leitora. In: FRADE, I. C. A. S.; COSTA VAL, M. G.; BREGUNCI, M. G. C. (org.). Glossário CEALE: termos de alfabetização, leitura e escrita para educadores. Belo Horizonte: UFMG/Faculdade de Educação, 2014. p. 61-62.

LAHIRE, Bernard. Sucesso escolar nos meios populares: as razões do improvável. São Paulo: Ática, 1997.

LAHIRE, Bernard. Homem Plural: os determinantes da ação. Petrópolis: Vozes, 2002.

LAJOLO, Marisa. Livro Didático: um (quase) manual de usuário. Em Aberto, Brasília, ano 16, n. 69, jan./mar. 1996.

PFAFF, Nicole. Etnografia em contextos escolares: pressupostos gerais e experiências interculturais no Brasil e na Alemanha. In: WELLER, Wivian; PFAFF, Nicolle. (orgs.). Metodologia da pesquisa qualitativa em Educação. Petrópolis, RJ: Vozes, 2013.

ROCHA, Helenice Aparecida B. O lugar da linguagem no ensino de história: entre a oralidade e a escrita. 2006. Tese (Doutorado em Educação) - UFF, Niterói, 2006.

ROCHA, Helenice Aparecida B. Livros didáticos de história: a diversidade de leitores e de usos. In: ROCHA, Helenice Aparecida B.; REZNIK, Luís; MAGALHÃES, Marcelo de Souza (orgs.). A História na Escola: autores, livros e leituras. Rio de Janeiro: Editora FGV, 2009. https://doi.org/10.17771/ pucrio.acad.19349 
SILVA, Marco Antonio. A formação leitora no livro didático de História. 2009. 229 f. Dissertação (Mestrado em Educação) - Universidade Federal de Minas Gerais, Belo Horizonte, 2009. https://doi.org/10.14393/19834071.2016.36 163

SILVA, Jeferson Rodrigo da. Artes de fazer o ensino de história: professor, aluno e livro didático entre saberes admitido e inventivo. 2012. 370 f. Dissertação (Mestrado em História Social) - Universidade Estadual de Londrina, Londrina, 2012. https://doi.org/10.20873/uft.2179-

3948.2018v9n3p178

SOLÉ, Isabel. Estratégias de leitura. Tradução Claúdia Schilling. Porto Alegre: Artmed: 1998.

Recebido em: 29/7/2017.

Aprovado em: 11/12/2018.

Publicado em: 8/11/2019.

Endereço para correspondência:

Lisiane Sias Manke

Rua General Neto, 1840 - Bl. G, Ap. 401

96015-280, Pelotas, RS, Brasil

\section{Autora:}

LISIANE SIAS MANKE

Doutora e Mestre em Educação pelo PPGE/FaE/UFPel. Graduada em História pela UFPel. Realizou estágio de pós-doc (CNPQ) na Universidade Federal de Minas Gerais, no PPGE/FaE. Professora do Departamento de História e do PPGH da Universidade Federal de Pelotas, Pelotas, RS, Brasil.

Orcid: https://orcid.org/0000-0001-5085-8791

E-mail: lisianemanke@yahoo.com.br 